\title{
Gibson assembly: an easy way to clone potyviral full-length infectious cDNA clones expressing an ectopic VPg
}

\author{
Amandine Bordat ${ }^{1,2}$, Marie-Christine Houvenaghel ${ }^{1,2}$ and Sylvie German-Retana ${ }^{1,2^{*}}$
}

\begin{abstract}
Background: Approaches to simplify and accelerate the construction of full-length infectious CDNA clones for plant potyviruses have been described, based on cloning strategies involving in vitro ligation or homologous recombination in yeast. In the present study, we developed a faster and more efficient in vitro recombination system using Gibson assembly (GA), to engineer a Lettuce mosaic virus (LMV) infectious clone expressing an ectopic mcherry-tagged VPg (Viral protein genome-linked) for in planta subcellular localization of the viral protein in an infection context.

Methods: Three overlapping long distance PCR fragments were amplified and assembled in a single-step process based on in vitro recombination (Gibson assembly). The resulting $17.5 \mathrm{kbp}$ recombinant plasmids (LMVmchVPg_Ec) were inoculated by biolistic on lettuce plants and then propagated mechanically on Nicotiana benthamiana. Confocal microscopy was used to analyze the subcellular localization of the ectopically expressed mcherry-VPg fusion protein.

Results: The Gibson assembly allowed the cloning of the expected plasmids without any deletion. All the inoculated plants displayed symptoms characteristic of LMV infection. The majority of the mcherry fluorescent signal observed using confocal microscopy was located in the nucleus and nucleolus as expected for a potyviral VPg.

Conclusions: This is the first report of the use of the Gibson assembly method to construct full-length infectious cDNA clones of a potyvirus genome. This is also the first description of the ectopic expression of a tagged version of a potyviral VPg without affecting the viability of the recombinant potyvirus.
\end{abstract}

Keywords: Full-length infectious clone, Gibson assembly, Potyvirus, VPg, Improved cloning

\section{Background}

The availability of full-length infectious cDNA clones (FL-cDNAs) is crucial for reverse genetics studies on plant viruses. Since the first description of the cloning of an infectious clone of Brome mosaic virus [1], many other infectious clones of plant RNA viruses were obtained by cloning the full-length genomic cDNA under T7 RNA polymerase or $35 \mathrm{~S}$ promoter sequences [2-4]. Approaches to simplify and accelerate the construction of FL-cDNAs for plant viruses were recently described, based on cloning strategies involving homologous recombination in yeast $[3,5]$ rather than more classical cloning approaches such as in vitro ligation. Furthermore, in the last few years, various methods

\footnotetext{
* Correspondence: german@bordeaux.inra.fr

'INRA, UMR 1332 de Biologie du Fruit et Pathologie, CS 20032, 33882 Villenave d'Ornon, France

Université de Bordeaux, UMR 1332 de Biologie du Fruit et Pathologie, CS 20032, 33882 Villenave d'Ornon, France
}

for assembling large DNA molecules have been developed [6]. In vitro assembly and yeast-based in vivo method were used in tandem to assemble the whole bacterial genome of Mycoplasma genitalium [7]. The development of in vitro methods allowed the synthesis of the first chemical mouse mitochondrial genome [8] using the isothermal assembly method called Gibson assembly [9]. This technique was further applied to construct animal viral genomes such as Dengue virus (DENV) [10] West nile virus (WNV) [11] and Porcine reproductive and respiratory syndrome virus (PRRSV) [12]. Animal viral genomes were even assembled de novo following chemical synthesis in the absence of natural template [13]. In the case of plant viruses, the development of synthetic cDNA clones was recently described for two members of the plant virus genera Tobamovirus and Tombusvirus [14, 15]. 
In this paper, we report the development of a rapid and efficient in vitro recombination system based on assembling overlapping PCR-amplified DNA molecules in a single isothermal step, derived from the strategy based on in vitro Gibson assembly (GA) [9]. This strategy was used to obtain modified infectious cDNA clones of a potyvirus, Lettuce mosaic virus (LMV). The genus Potyvirus is the largest genus of plant viruses, causing considerable economic losses in various crops $[16,17]$. Potyviruses have flexuous filamentous particles containing a positive single-stranded RNA, covalently linked to a viral protein genome-linked (VPg) at its 5' end. The genome encodes a large polyprotein processed by three self-encoded proteinases to yield the mature viral proteins [17]. In recent years, components of the eukaryotic translation initiation complex were identified as essential determinants in the outcome of potyviral infection [18]. In particular, we have shown that the recessive resistance to LMV is conferred by the lettuce $m o 1$ gene, encoding the eukaryotic translation initiation factor 4E (eIF4E) [19-21]. We demonstrated that the VPg together with the Cylindrical inclusion helicase $(\mathrm{CI})$ are directly involved in overcoming $m o 1$ resistance $[22,23]$ and in binding to lettuce eIF4E [24]. Such interactions should play crucial roles in many processes during the virus infection cycle, and probably during the eIF4E recruitment process.

In the context of deciphering the contribution of the VPg protein to lettuce-LMV interactions we aimed at engineering LMV FL-cDNA clones expressing a mcherry-tagged VPg (LMVmchVPg), in order to perform in planta subcellular localization of this viral protein in infected cells. For that purpose, we initially engineered a recombinant LMV expressing the mcherry protein fused to either the $\mathrm{N}$-terminal or the C-terminal ends of the VPg, using homologous recombination in yeast to assemble overlapping DNA fragments. Unfortunately, LMV variants with deletions of the inserted mcherry gene were rapidly selected in planta, showing that the mcherrytagging of the VPg significantly affected the fitness of LMV (data not shown). To solve this problem, we engineered LMV recombinants expressing an ectopic form of mcherry-tagged VPg in addition of the native VPg (LMVmchVPg_Ec), using the Gibson assembly method [9]. This is the first report of a recombinant potyvirus infectious cDNA clone obtained using Gibson assembly, as well as the first description of the ectopic expression of a potyviral VPg without affecting the viability of the recombinant potyvirus vector.

\section{Results and discussion}

\section{Construction of an LMV FL-CDNA clone expressing a} mcherry-tagged VPg using Gibson assembly method

The genome of the final expected construct, named LMVmchVPg_Ec, is represented on Fig. 1a. The mcherry sequence is fused at the $\mathrm{N}$-terminus of the VPg and the
mcherry-VPg fusion gene is cloned between the P1 and HC-Pro coding sequences, at the cloning site currently used for LMV engineering $[25,26]$. Indeed, tag insertions between NIb and CP were tried for LMV but led to a decrease in LMV infection (unpublished results). In an effort to preserve the biological properties of the parental LMV isolate, an artificial cleavage site for the NIa viral proteinase (DEVYHQ/SG) was inserted at the end of the ectopic mcherry-VPg sequence, allowing the recovery of an unfused HC-Pro protein following proteolytic maturation of the polyprotein [26]. The cloning strategy used to assemble this construct is described in Fig. 1b. Two divergent overlapping PCR fragments (F1 and F2) of respectively $8.5 \mathrm{kbp}$ and $7.7 \mathrm{kbp}$, corresponding to the LMV infectious CDNA and to the cloning vector, were amplified from a LMV cDNA clone described in a previous study [23] and derived from the LMV-0 isolate [GenBank: X9770]. The F1 and F2 fragments were respectively amplified with the primers pairs F1.fwd/F1.rev and F2.fwd/F2.rev (Table 1). The mcherry-VPg (mchV) sequence was amplified from LMVmchVPg template (Additional files 1 and 2) with the primers mchV.fwd and mchV.rev listed in Table 1. The three purified overlapping fragments (F1, F2 and mchV) were further assembled in one single-step reaction by GA. The efficiency of the GA in vitro recombination reaction was evaluated by agarose gel electrophoresis analysis (Fig. 2). The red arrow points out the high-molecular weight fragment corresponding to the recombination product obtained after the GA reaction (Fig. 2, lane 1). The majority of the PCR fragments disappeared after the GA reaction (compare Fig. 2 lane 1 and lane 2, negative control). In our experience, a key point for Gibson assembly strategy is to design the overlapping zone of the PCR amplified fragments. Indeed, during the GA reaction, the T5 exonuclease removes nucleotides from the $5^{\prime}$ end of each PCR fragment, releasing single stranded ends that can form secondary structure, such as hairpins. This may impair the annealing of the overlapping fragments and therefore reduce the efficiency of the in vitro recombination. Therefore, the position of the primers for long distance PCR amplification must be carefully chosen to avoid this situation.

After transformation of the recombination product in E.coli cells, 30 colonies were obtained. Plasmid was extracted from 24 colonies and restriction enzyme analysis showed that 12 colonies contained plasmids with the expected restriction profile. Two independent LMVmchVPg_Ec clones, LV14 and LV15, were chosen for further analysis.

Infectivity of LMVmchVPg_Ec clones in lettuce plants Purified DNA of the LMVmchVPg_Ec clones LV14 and LV15 were coated on gold particles and inoculated by 

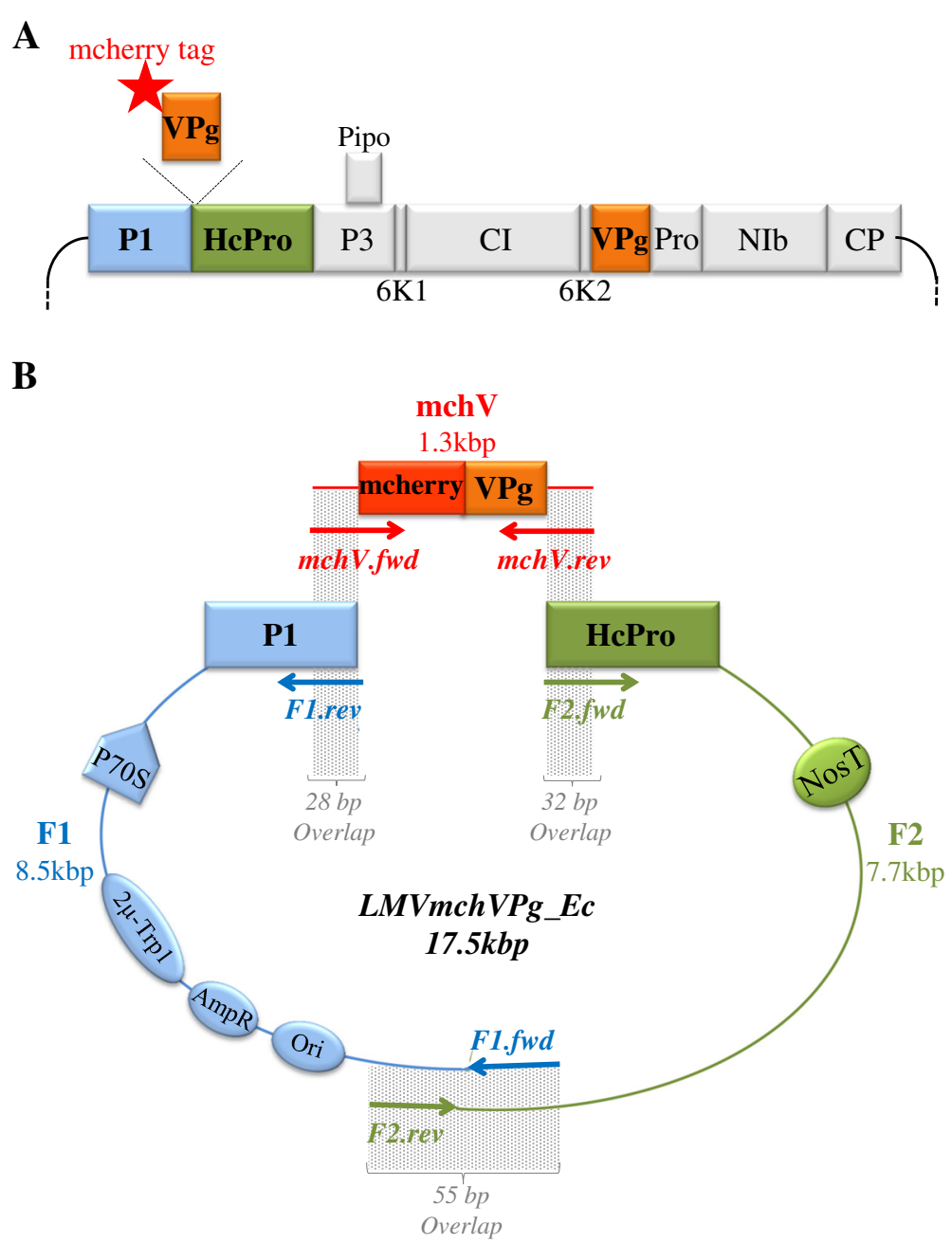

Fig. 1 Cloning of LMVmchVPg_Ec full-length cDNA by in vitro recombination Gibson assembly strategy. a Schematic representation of the infectious clone LMVmchVPg_Ec genome. The ectopically expressed mcherry-VPg fusion protein gene is inserted between the P1 and HcPro sequences of the Lettuce mosaic virus (LMV) genome (red star: mcherry fluorescence tag fused at the N-terminus of the VPg). b Schematic representation of the cloning by in vitro recombination strategy. The size of the overlapping regions between the PCR fragments where recombination takes place is indicated. The three overlapping fragments named mchV, F1 and F2 (highlighted in red, blue and green respectively) were amplified by long distance PCR using the primers pairs (arrows) positioned along the cloning vector or the viral LMV template. The full-length CDNA of LMV is derived from the LMV-0 CDNA clone previously reported by Redondo et al. [30] and further modified by Sorel et al. [23]. The LMV FL- cDNA was assembled into a pBluescribe-derived vector pBS70T containing an enhanced 355 promoter (P70S), a NOS terminator (NosT), an E.coli replication origin (Ori), an ampicillin resistance gene $(\mathrm{AmpR})$, a cassette containing the $2 \mu$ yeast replication origin and a yeast selectable marker (Trp-1 promoter and gene, $2 \mu$-Trp1).The three PCR products were assembled in vitro by Gibson assembly. bp: base pair; kbp: kilobase pair

particle bombardment on six plants each of the susceptible lettuce cultivar Trocadéro. At 15 days after inoculation (dpi), all the inoculated plants displayed the characteristic vein clearing and mosaic symptoms of LMV infection on the systematically infected leaves (Additional file 3). The expression of the mcherry-VPg fusion was first examined in systemic leaves using a fluorescence stereomicroscope. Under UV light, the fluorescence signal (Fig. 3b, d) overlapped with the mosaic symptoms pattern observed under white light (Fig. 3a, c) confirming the replication and systemic propagation of both LMVmchVPg_Ec clones. The presence of the recombinant virus was confirmed by reverse transcriptionPCR using LMV-specific primers P1Hc.fwd and P1Hc.rev (Table 1) targeting the insertion site of the ectopically mcherryVPg fusion (Additional file 4).

\section{Subcellular localization of mcherry-VPg fusion protein in infected leaves}

The subcellular localization of the mcherry-VPg fusion expressed in lettuce and in $N$. benthamiana (another LMV host currently used for transient expression of tagged protein by agroinfiltration), was further analyzed using confocal microscopy. At $20 \mathrm{dpi}$, the majority of 
Table 1 List of primers used for LMVmchVPg_Ec cloning and RT-PCR amplification

\begin{tabular}{lllll}
\hline $\begin{array}{l}\text { Primer } \\
\text { name }\end{array}$ & $\begin{array}{l}\text { Primer } \\
\text { size }(\mathrm{nt})\end{array}$ & $\begin{array}{l}\text { Amplified } \\
\text { fragment }\end{array}$ & Sequence 5'-3' & Product size (kbp) \\
\hline F1.fwd & 30 & F1 & GCGGATCCAAAGGATAATATCATCACAGAG & 8.5 \\
F1.rev & 28 & & GTATTGAACCATACGGTGCGTGATGGAG & 7.7 \\
F2.fwd & 49 & F2 & GACGAAGTATACCACCAGTCCGGAGACGTCGCACGAAACTTCTGGAACG & 1.3 \\
F2.rev & 23 & & CTTCTTCATCTGCCCAGAACCAC & CTCCATCACGCACCGTATGGTTCAATACAGTGATGTAGTGAGCAAGGGCGAGGAGGAT \\
mchV.fwd & 58 & mchV & TGCGACGTCTCCGGACTGGTGGTATACTTCGTCTTCGTGCTTACAGGGATG & 1.9 \\
mchV.rev & 52 & & GGCGACACAGTATATTCGT & \\
P1Hc.fwd & 20 & 3'P1-mchVPg-5'HCPro & & \\
P1Hc.rev & 21 & & TCACTAAAGTCATTCAGGAAC & \\
\hline
\end{tabular}

The regions of homology allowing in vitro recombination between fragments are indicated in bold. The artificial Nla cleavage site is indicated in italics. The primers P1Hc.fwd and P1Hc.rev were used to perform RT-PCR to confirm the presence of the mcherry-VPg gene expression in the viral progeny. The suffixes "fwd" indicate sense primers, while suffixes "rev" indicated antisense primers. nt nuclotides, $b p$ base pair

the fluorescence signal was found in the nucleus and nucleolus of the infected lettuce cells (Fig. 4) or infected $N$. benthamiana cells (Fig. 5). The localization of the VPg to the nucleus was confirmed by DAPI staining of nuclear DNA (Additional file 5). The nuclear VPg localization was already observed for other potyviral VPg [27]. In particular, in 2009, Rajamaki and Valkonen showed that the VPg of Potato virus $A$ accumulates in the nucleolus and interacts with fibrillarin [28]. They

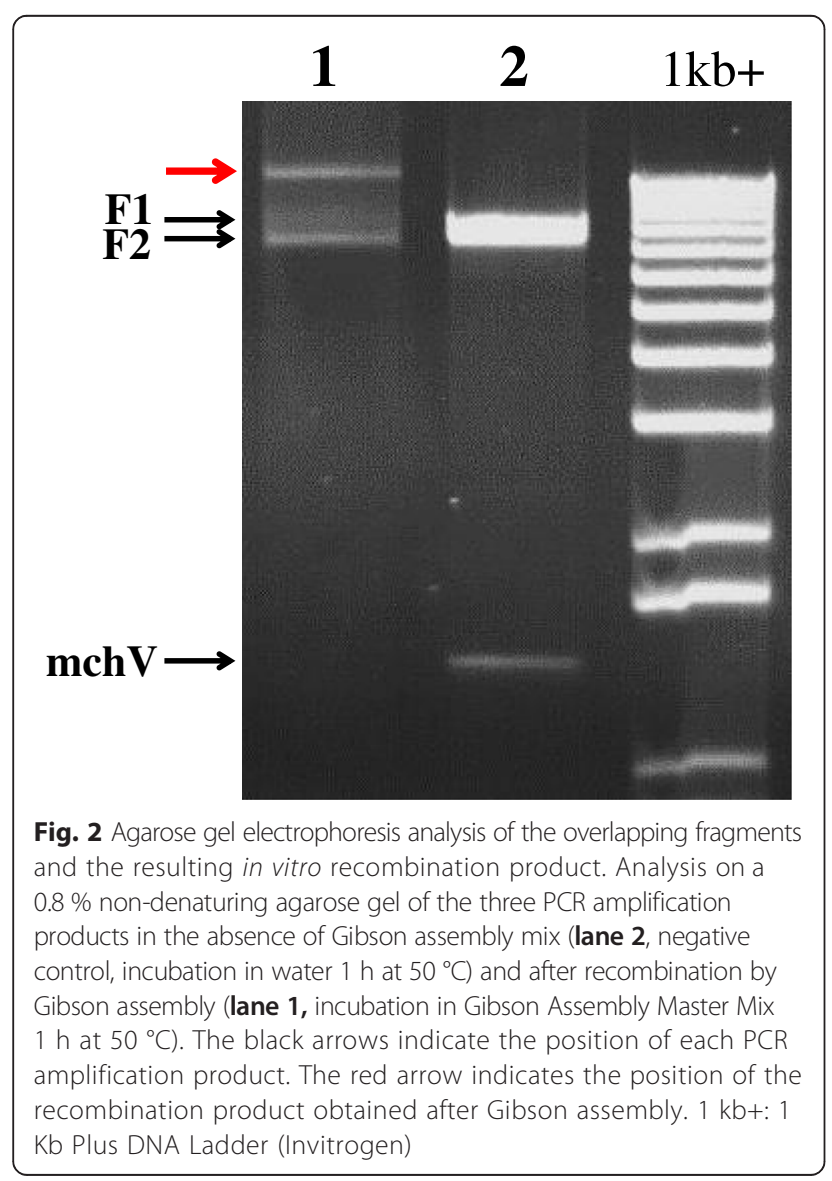

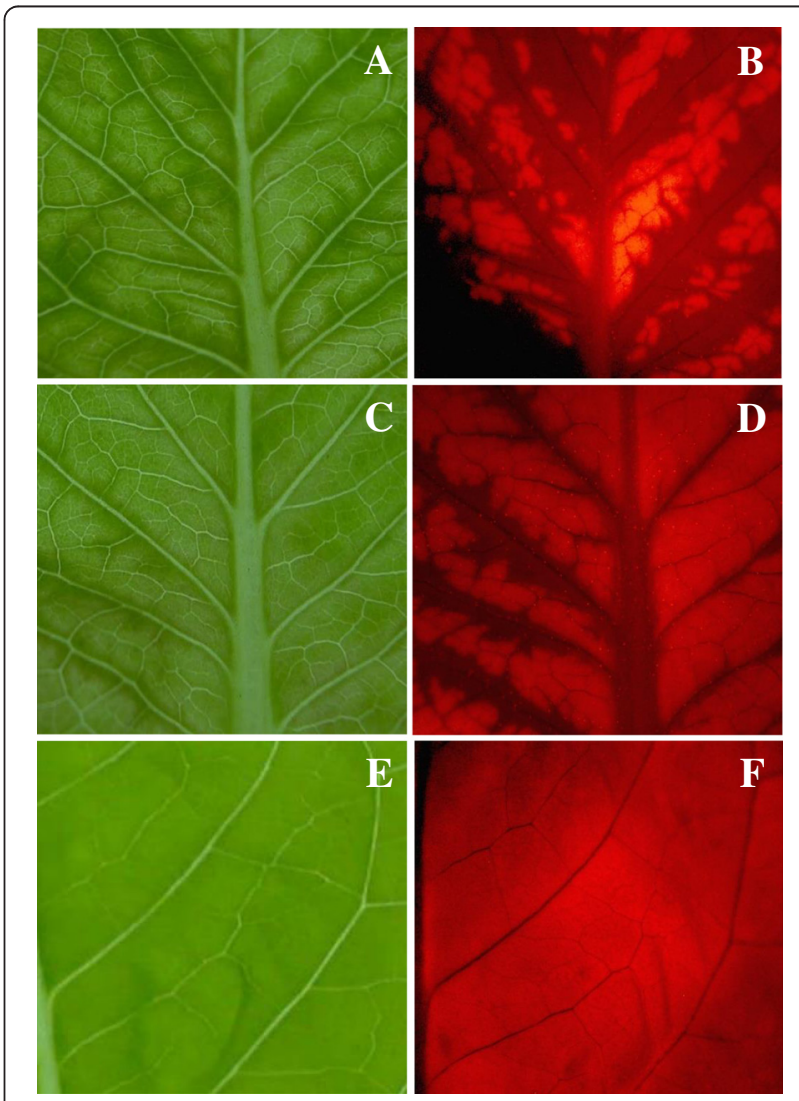

Fig. 3 Symptoms induced by LMVmchVPg_Ec on the lettuce cultivar Trocadéro under white and UV light. The mcherry-VPg expression in systemically infected leaves, was examined by fluorescence microscopy with a $0.8 \times$ magnification, using a Leica MZFLIII Fluorescence Stereomicroscope. a-d: Plants infected with LMVmchVPg_Ec (clone LV15) at 15 days post inoculation (dpi) under white light (a, $\mathbf{c}$ ) and UV light (b, d). The fluorescence is superimposable to yellow-green areas of the mosaic symptoms pattern observed under white light. e-f: mock-inoculated Trocadéro plants under white light (e) and UV light (f) 


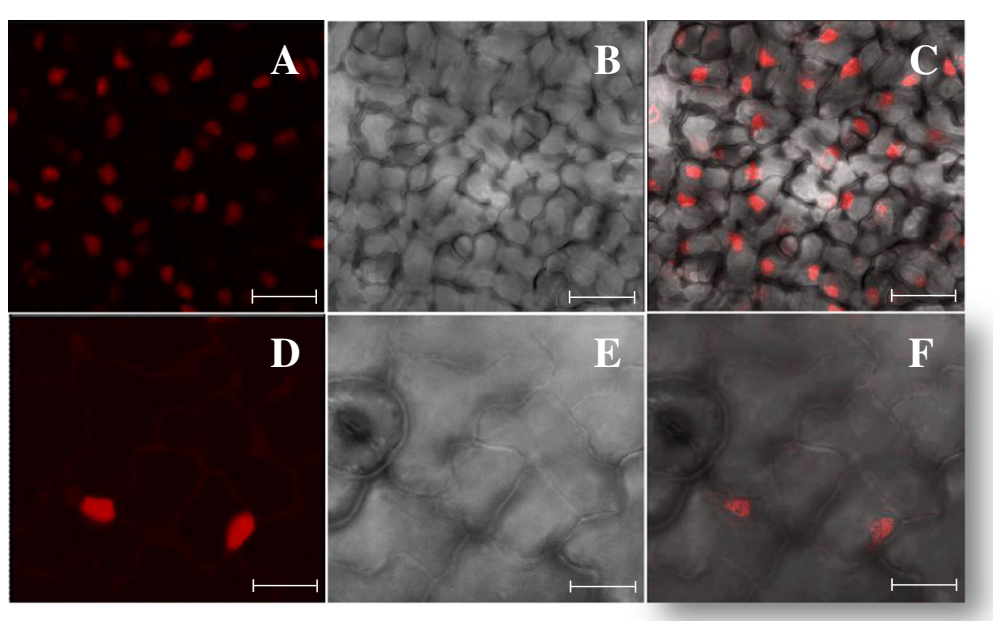

Fig. 4 Detection of fluorescence emitted by the fusion protein mcherry-VPg in LMVmchVPg_Ec infected lettuce leaves. Fluorescence signals observed in the epidermal cells of the lettuce cultivar Trocadéro by confocal microscopy. Images for fluorescence emitted by mcherry-VPg at $20 \mathrm{dpi}(\mathbf{a}, \mathbf{d})$. Bright field images of the same cells (b, e) and corresponding overlay images (c, f). Scale bars: $27.39 \mu \mathrm{M}(\mathbf{a}, \mathbf{b}, \mathbf{c}), 15 \mu \mathrm{M}(\mathbf{d}, \mathbf{e}, \mathbf{f})$

also showed that a bipartite nuclear localization signal (NLS) sequence mediates nuclear/nucleolar localization of the VPg which is crucial for viral replication. Concerning LMV, VPg residues two to eight (KGKRQRQ) are predicted to form a NLS in plant cells, according to functional prediction of the Eukaryotic Linear Motif
(ELM) data base (http://elm.eu.org/) [29]. In this study, the subcellular localization of the mcherry-VPg ectopically expressed from LMV genome is therefore in good agreement with previous results and confirms that the mcherry-fusion does not alter the subcellular localization of the VPg. The recombinant LMVmchVPg_Ec clone
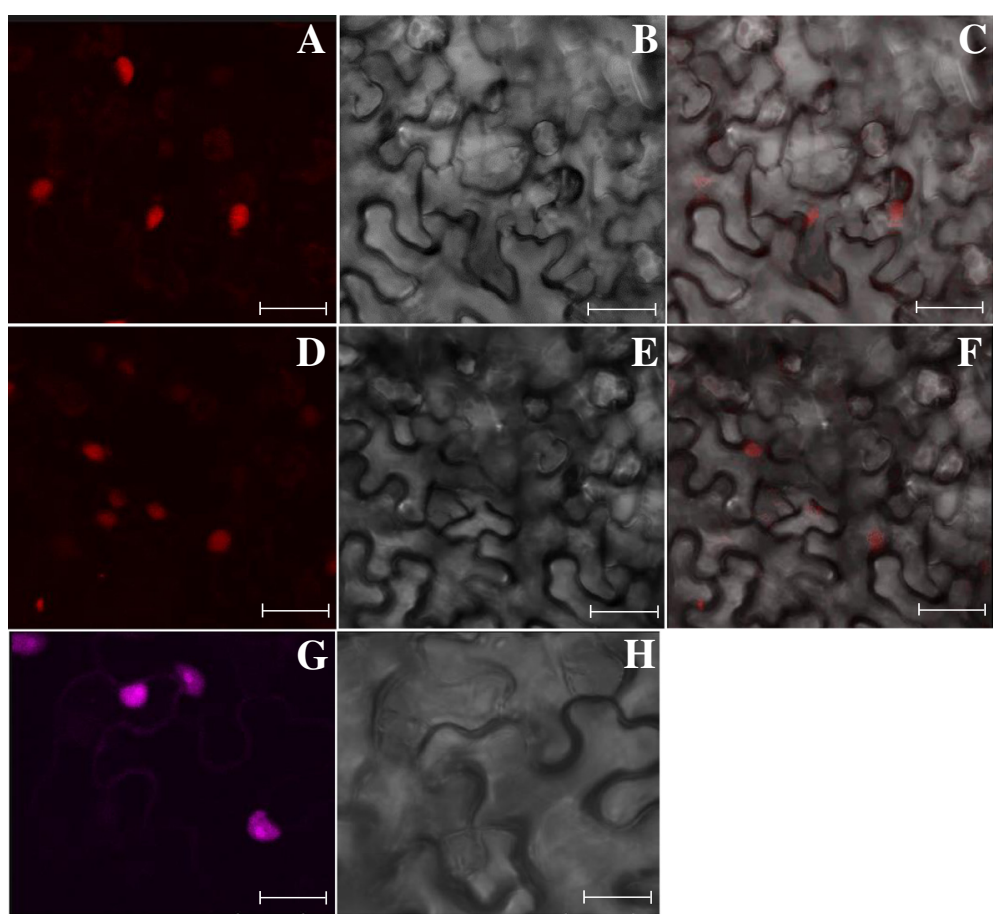

Fig. 5 Detection of fluorescence emitted by the fusion protein mcherry-VPg in LMVmchVPg-Ec infected Nicotiana benthamiana leaves. Fluorescence signals observed in the epidermal cells of Nicotiana benthamiana by confocal microscopy. Images for fluorescence emitted by mcherry-VPg at $16 \mathrm{dpi}$ $(\mathbf{a}, \mathbf{d}, \mathbf{g})$. Bright field images of the same cells $(\mathbf{b}, \mathbf{e}, \mathbf{h})$ and corresponding overlay images $(\mathbf{c}, \mathbf{f})$. The fluorescence signal in the nucleolus is particularly strong in the nuclei observed in $\mathbf{g}$. Scale bars: $27.23 \mu \mathrm{M}(\mathbf{a}, \mathbf{b}, \mathbf{c}), 28 \mu \mathrm{M}(\mathbf{d}, \mathbf{e}, \mathbf{f}), 18.9 \mu \mathrm{M}(\mathbf{g}, \mathbf{h})$ 
will be useful to investigate the subcellular localization of the interactions between the VPg and its viral partners during LMV infection. In particular, the CI protein will be transiently expressed by agroinfiltration as a GFPfusion protein in LMVmchVPg_Ec infected plants. The observation of the GFP and mcherry signals by confocal microscopy will allow us to precisely place where the $\mathrm{VPg}-\mathrm{CI}$ interaction takes place.

\section{Conclusions}

Full-length infectious cDNA clones are crucial for reverse genetics studies on plant RNA viruses. In this paper, we describe a significant methodological advance to simplify and accelerate the construction of infectious cDNA clones derived from the potyvirus Lettuce mosaic virus as a model example. This approach relies on an in vitro recombination system called Gibson assembly (GA), based on assembling and repairing overlapping PCR-amplified DNA molecules in a single isothermal step (Additional file 6). In our opinion, this constitutes proof of concept of the use of Gibson assembly to create a recombinant potyvirus genome. Using this GA-based strategy, we modified the LMV genome in order to ectopically express a mcherry-tagged VPg fusion protein during viral infection. We showed that this modification did not affect the viability of the recombinant potyvirus in contrast to direct tagging of the VPg. The mcherryVPg fusion protein was observed in the nucleus and nucleolus of infected cells as expected, confirming that the fusion did not affect the subcellular localization of the VPg. The recombinant LMVmchVPg_Ec clone should prove a very interesting tool to further investigate the subcellular localization of the VPg and its viral and cellular partners during LMV infection.

\section{Methods \\ Full-length cDNA amplification of overlapping DNA fragments using long distance PCR}

The design of the primers was based on "classic" criteria such as avoiding regions of secondary structure and selfannealing, aiming for the GC content to be between 40 and $60 \%$ with three $\mathrm{C}$ or $\mathrm{G}$ at the $3^{\prime}$ of a primer ending to promote binding. The PCR mixture contained $1 \mathrm{X}$ PCR buffer, $0.5 \mu \mathrm{M}$ of each primer, $0.2 \mathrm{mM}$ dNTPs mix and 0.02U. $\mathrm{l}^{-1}$ of Phusion ${ }^{\circ}$ High-Fidelity DNA polymerase (New England BioLabs). PCR reactions contained 5-10 ng of template plasmid and were carried out under the following conditions: the initial denaturation of $30 \mathrm{~s}$ at $98{ }^{\circ} \mathrm{C}$, followed by 35 cycles of 10 s at $98 \mathrm{C}, 30 \mathrm{~s}$ at $68^{\circ} \mathrm{C}, 40$ s per $\mathrm{kb}$ at $72{ }^{\circ} \mathrm{C}$, followed by a final elongation of $5 \mathrm{~min}$ at $72^{\circ} \mathrm{C}$. All amplified fragments were purified using the PCR clean-up Gel extraction kit (Macherey-Nagel) according to the manufacturer's instructions and then digested by the $D p n \mathrm{I}$ restriction enzyme (1X buffer, 0.5U.jl-1 of DpnI). As DpnI recognizes 5'-GmeATC-3' sites and digests the methylated DNA, it was used to degrade the plasmid template following PCR reactions. A final purification step using the PCR clean-up Gel extraction kit was applied to clean-up PCR products after digestion.

\section{In vitro recombination by Gibson assembly}

The three clean-up PCR fragments (F1, F2, mchV, see Fig. 1b) were assembled according to the one-step isothermal DNA assembly method described by Gibson in 2009 [9]: 0.025 pmol of each DNA fragments were pooled in $5 \mu \mathrm{l}$, and $15 \mu \mathrm{l}$ of home -made assembly master mixture according to Gibson's protocol $(500 \mathrm{mM}$ Tris- $\mathrm{HCl} \mathrm{pH}$ 7.5, $50 \mathrm{mM} \mathrm{MgCl}$, $1 \mathrm{mM} \mathrm{dGTP,} 1 \mathrm{mM}$ dATP, $1 \mathrm{mM}$ dTTP, $1 \mathrm{mM}$ dCTP, $50 \mathrm{mM}$ DTT, $25 \%$ PEG-8000 and $5 \mathrm{mM}$ NAD) were added to DNAs. The mixture was incubated at $50{ }^{\circ} \mathrm{C}$ for $1 \mathrm{~h}$ in a thermocycler. In order to control DNA molecules assembly, a $0.8 \%$ agarose gel electrophoresis was performed in $1 \mathrm{X}$ TBE buffer, and DNA stained with ethidium bromide $(5 \mu \mathrm{g} / \mathrm{mL})$ for visualization. Three microliters of Gibson assembly reaction were used for transformation of NEB 10-beta Electrocompetent E.coli cells according to the manufacturer's recommendations (New Englands Biolabs). Bacterial plasmid DNA extraction was performed using Wizard ${ }^{\circledR}$ Plus SV Minipreps DNA Purification System kit and protocols (Promega) according to the manufacturer's instructions. Restriction analysis of the purified plasmids was performed with two different enzymes EcoRV and HindIII (1X buffer, $1 \mathrm{X}$ BSA, $0.5 \mathrm{U} / \mu \mathrm{l})$.

\section{Plant inoculation}

All plants were grown under standard greenhouse conditions ( $16 \mathrm{~h}$ day length; $18-23{ }^{\circ} \mathrm{C}$ ). To check the infectivity of the FL-cDNA clones, two independent LMVmchVPg_Ec cDNA clones (LV14, LV15) were inoculated as described previously [30] using DNA-coated gold particle bombardment with an Helios ${ }^{\circ}$ Gene Gun System (Bio-Rad). Each clone was inoculated to six lettuce plants (Lactuca sativa, cultivar Trocadéro) in two independent experiments. The upper systemically infected leaves of primarily inoculated by biolistic with the LV15 clone were then used to mechanically inoculate one Trocadéro lettuce and three Nicotiana benthamiana plants, in four independent experiments. The infected leaves were ground (ratio 1:4 wt/vol) in a solution of $25 \mathrm{mM} \mathrm{Na}_{2} \mathrm{HPO}_{4}$ containing $0.2 \%$ diethyldithiocarbamate (DIECA) and $100 \mathrm{mg}$ of carborundum.

\section{RNA extraction and RT-PCR}

Total RNAs were extracted from fresh symptomatic systemically infected leaves as previously described [31]. The presence of the mcherry-VPg fusion in the recombinant virus was confirmed by two-step RT-PCR. The reverse transcription was started by mixing $5 \mu \mathrm{g}$ of total 
RNAs with $1 \mu \mathrm{M}$ of oligo (dT) 18 primer and $2 \mu \mathrm{M}$ of random hexamer primer (N6) in a volume of $12 \mu \mathrm{l}$. To disrupt potential secondary structures, the tube was placed $5 \mathrm{~min}$ at $65{ }^{\circ} \mathrm{C}$, before adding $8 \mu \mathrm{l}$ of 10 units RevertAid $^{\mathrm{TM}} \mathrm{H}$ Minus (Thermo Fisher Scientific Inc.), 1 unit RiboLock ${ }^{\text {Ti }}$ RNAse Inhibitor (Thermo Fisher Scientific Inc.), $1 \mathrm{X}$ buffer and $1 \mathrm{mM}$ dNTP. The reverse transcription reaction was performed at $25{ }^{\circ} \mathrm{C}$ for $10 \mathrm{~min}$, $42{ }^{\circ} \mathrm{C}$ for $60 \mathrm{~min}$ and $70{ }^{\circ} \mathrm{C}$ for $10 \mathrm{~min}$. Following firststrand synthesis, $2 \mu \mathrm{l}$ of cDNA were transferred to a separate tube for the PCR step involving $2 \mu \mathrm{M}$ of each of the two primers - P1Hc.fwd and P1Hc.rev - targeting the insertion site of the ectopic mcherryVPg sequence (Table 1), 1X ThermoPol $^{\circ}$ buffer, $0.25 \mathrm{mM}$ dNTP and 0.05 units Taq DNA polymerase (New England Biolabs). PCR amplification was performed with an initial denaturation step at $95{ }^{\circ} \mathrm{C}$ for $2 \mathrm{~min}$, followed by 35 cycles each consisting of $30 \mathrm{~s}$ at $95{ }^{\circ} \mathrm{C}, 30 \mathrm{~s}$ at $56^{\circ} \mathrm{C}$ and $2 \mathrm{~min}$ at $72{ }^{\circ} \mathrm{C}$, and a final step final elongation at $72{ }^{\circ} \mathrm{C}$ for $5 \mathrm{~min}$. The amplification products were analyzed on $0.8 \%$ non-denaturing agarose gels and ethidium bromide staining. Their sequence was confirmed by direct sequencing (GATC Biotech Constance, Germany) on both strands.

\section{Fluorescence and confocal microscopy observations}

The mcherry expression at the tissue level was examined by fluorescence microscopy with a $0.8 \times$ magnification, using a Leica MZFLIII Fluorescence Stereomicroscope equipped with TXR LP (Texas Red Long Pass) Filter (excitation BP: 540-580 nm), emission LP: $601 \mathrm{~nm}$ (Eclipse 800, Nikon, Tokyo, Japan). Subcellular distribution of mCherry fluorescence was analyzed using a Leica TCS SP2 confocal microscope and the LCS Lite Leica software. mcherry fluorescence was assessed with excitation at $543 \mathrm{~nm}$ using a Helium-Neon (HeNe) laser, with an emission band of 560-645 nm. The fluorescence of DAPI characteristic of nucleus labelling was assessed with excitation at $40 \mathrm{~nm}$ and emission bands of $410 \mathrm{~nm}$ to $475 \mathrm{~nm}$.

\section{Additional files}

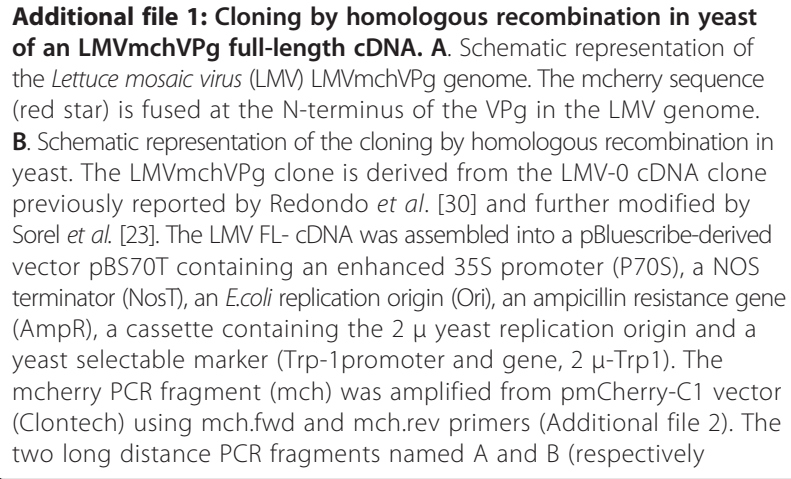

highlighted in green and orange) were amplified by long distance $P C R$, using the primer pairs (Additional file 2) positioned along the LMV FL-CDNA clone described in Sorel et al. [23]. The size of the overlapping regions between the $\mathrm{PCR}$ fragments where homologous recombination takes place is indicated. Homologous recombination in yeast of the three fragments was performed according to Sorel et al. [23]. bp: base pair; kbp: kilobase pair.

Additional file 2: Primers used for the LMVmchVPg cloning by homologous recombination in yeast. The regions of homology allowing recombination in yeast are underlined and indicated in bold. The suffixes "fwd" indicate sense primers, while suffixes "rev" indicate antisense primers. bp: base-pair, nt: nucleotide.

Additional file 3: Vein clearing and mosaic symptoms characteristic of LMV infection induced by LMVmchVPg_Ec on lettuce. A. mockinoculated lettuce. B, C. vein clearing symptoms (B) and mosaic symptoms (C) induced on the upper systemically infected leaves at $15 \mathrm{dpi}$.

Additional file 4: Detection by RT-PCR of LMVmchVPg_Ec progeny in systemically infected leaves of lettuce at $15 \mathrm{dpi}$. $0.8 \%$ non-denaturing agarose gel electrophoresis of the reverse transcription-polymerase chain reaction (RT-PCR) amplification products obtained with primers P1Hc.fwd and P1Hc.rev in total RNAs extracts from LMVmchVPg-Ec infected plants (LV) or healthy plants $(\mathbf{H})$. Controls: amplification product obtained with the plasmid template LMVmchVPg_Ec $(\mathbf{C}+)$ or with the plasmid template LMV (without mcherry-VPg) (C-). 1 kb+: 1 Kb Plus DNA Ladder (Invitrogen). The relevant sizes of the expected DNA fragments are indicated at the left.

Additional file 5: DAPI staining of LMVmchVPg_Ec infected lettuce leaves. A. Fluorescence signals observed in the epidermal cells of the lettuce cultivar Trocadéro using confocal microscopy at $16 \mathrm{dpi}$. B. DAPI staining: the leaf was infiltrated with $0.4 \mu \mathrm{M} / \mathrm{ml}$ diamidino-2-phenylindole (DAPI). The fluorescence of DAPI was assessed with excitation at $40 \mathrm{~nm}$ and emission bands of 410 to $475 \mathrm{~nm}$. Scale bars: $16.1 \mu \mathrm{M}$ (A, B).

Additional file 6: Flow-chart of the different steps of the procedure.

\section{Abbreviations}

LMV: Lettuce mosaic virus; VPg: Viral protein genome-linked; dpi: Day post inoculation; GA: Gibson assembly; bp: Base pair; FL-cDNA: Full length complementary DNA; RT-PCR: Reverse transcription-polymerase chain reaction; dNTP: Deoxyribonucleotide triphosphate; DTT: Dithiothreitol; NAD: Beta-nicotinamide adenine dinucleotide; TBE: Tris borate EDTA; EDTA: Ethylenediaminetetraacetic acid; SDS-PAGE: Sodium dodecylsulfate polyacrylamide gel electrophoresis.

\section{Competing interests}

The authors declare that they have no competing interests.

\section{Authors' contributions}

AB performed GA cloning, infection assays and wrote the manuscript. SGR supervised the study, performed Nicotiana benthamiana infections, carried out microscopy observations and wrote the manuscript. MCH participated in the preparation of the initial synthetic CDNA clone and performed inoculations. All authors read and approved the final manuscript.

\section{Acknowledgments}

We are grateful to Carole Lartigues and Thierry Candresse for useful discussion about Gibson assembly cloning strategy and for revision of the manuscript. We thank the greenhouse team members for providing and taking care of the plants. This work was supported by a grant from the INRA SPE Department of the Institut National de la Recherche Agronomique (INRA) (2012-2014). We thank the members of the 'Pôle imagerie du Végétal' of the Bordeaux Imaging Center (BIC, www.bic.u-bordeaux.fr) for their help with the confocal microscopy observations.

Received: 7 April 2015 Accepted: 29 May 2015

Published online: 14 June 2015

\section{References}

1. Ahlquist P, Janda M. CDNA cloning and in vitro transcription of the complete brome mosaic virus genome. Mol Cell Biol. 1984;4:2876-82. 
2. Boyer J, Haenni A. Infectious transcripts and CDNA clones of RNA viruses. Virology. 1994;198:415-26.

3. Youssef F, Marais A, Faure C, Gentit P, Candresse T. Strategies to facilitate the development of uncloned or cloned infectious full-length viral CDNAs: Apple chlorotic leaf spot virus as a case study. Virol J. 2011;8:488.

4. Junqueira BRT, Nicolini C, Lucinda N, Orílio AF, Nagata T. A simplified approach to construct infectious CDNA clones of a tobamovirus in a binary vector. J Virol Methods. 2014;198:32-6.

5. Desbiez C, Chandeysson C, Lecoq H, Moury B. A simple, rapid and efficient way to obtain infectious clones of potyviruses. J Virol Methods. 2012;183:94-7.

6. Patron NJ. DNA assembly for plant biology: techniques and tools. Curr Opin Plant Biol. 2014;19C:14-9.

7. Gibson DG, Benders GA, Andrews-Pfannkoch C, Denisova EA, Baden-Tillson $\mathrm{H}$, Zaveri J, et al. Complete chemical synthesis, assembly, and cloning of a Mycoplasma genitalium genome. Science. 2008;319:1215-20.

8. Gibson DG, Smith HO, Hutchison CA, Venter JC, Merryman C. Chemical synthesis of the mouse mitochondrial genome. Nat Methods. 2010;7:901-3.

9. Gibson DG, Young L, Chuang RY, Venter JC, Hutchison CA, Smith HO. Enzymatic assembly of DNA molecules up to several hundred kilobases. Nat Methods. 2009:6:343-5.

10. Siridechadilok B, Gomutsukhavadee M, Sawaengpol T, Sangiambut S, Puttikhunt C, Chin-Inmanu K, et al. A Simplified Positive-Sense-RNA Virus Construction Approach That Enhances Analysis Throughput. J Virol. 2013:87:12667-74.

11. Vandergaast R, Hoover LI, Zheng K, Fredericksen BL. Generation of west nile virus infectious clones containing amino Acid insertions between capsid and capsid anchor. Viruses. 2014;6:1637-53.

12. Suhardiman M, Kramyu J, Narkpuk J, Jongkaewwattana A, Wanasen N. Generation of porcine reproductive and respiratory syndrome virus by in vitro assembly of viral genomic cDNA fragments. Virus Res. 2015;195:1-8.

13. Wimmer E, Mueller S, Tumpey TM, Taubenberger JK. Synthetic viruses: a new opportunity to understand and prevent viral disease. Nat Biotechnol. 2009;27:1163-72

14. Cooper B. Proof by synthesis of Tobacco mosaic virus. Genome Biol. 2014;15:R67.

15. Lovato A, Faoro F, Gambino G, Maffi D, Bracale M, Polverari A, et al. Construction of a synthetic infectious CDNA clone of Grapevine Algerian latent virus (GALV-Nf) and its biological activity in Nicotiana benthamiana and grapevine plants. Virol J. 2014;11:186.

16. Adams MJ, Zerbini FM, French R, Rabenstein F, Stenger DC, Valkonen JPT. Family potyviridae. In: AMQ King, MJ Adams, EB Carstens \& EJ Lefkowitz, editors. Virus Taxonomy, Ninth Report of the International Committee on Taxonomy of Viruses. 2011, 1069-1089.

17. Revers F, Garcia JA. Molecular Biology of Potyviruses. Advances in Virus Research Chapter three. 2015:92:101-99.

18. Wang A, Krishnaswamy S. Eukaryotic translation initiation factor 4E-mediated recessive resistance to plant viruses and its utility in crop improvement. Mol Plant Pathol. 2012;13(7):795-803.

19. Nicaise V, German-retana S, Sanjua R, Dubrana M, Mazier M, Maisonneuve B, et al. The Eukaryotic Translation Initiation Factor 4E Controls Lettuce Susceptibility to the Potyvirus. Plant Physiol. 2003;132:1272-82.

20. German-Retana S, Walter J, Doublet B, Roudet-Tavert G, Nicaise V, Lecampion $C$, et al. Mutational analysis of plant cap-binding protein elF4E reveals key amino acids involved in biochemical functions and potyvirus infection. J Virol. 2008;82:7601-12

21. German-Retana S, Walter J, Le Gall O. Lettuce mosaic virus: From pathogen diversity to host interactors. Mol Plant Pathol. 2008;9:127-36.

22. Abdul-Razzak A, Guiraud T, Peypelut M, Walter J, Houvenaghel MC, Candresse T, et al. Involvement of the cylindrical inclusion (Cl) protein in the overcoming of an elF4E-mediated resistance against Lettuce mosaic potyvirus. Mol Plant Pathol. 2009:10:109-13.

23. Sorel M, Svanella-Dumas L, Candresse T, Acelin G, Pitarch A, Houvenaghel $M$, et al. Key mutations in the Cylindrical Inclusion involved in Lettuce mosaic virus adaptation to elF4E-mediated resistance in lettuce. Mol Plant-Microbe Interact. 2014;9:1014-24.

24. Tavert-Roudet G, Abdul-Razzak A, Doublet B, Walter J, Delaunay T, German-Retana $\mathrm{S}$, et al. The $\mathrm{C}$ terminus of lettuce mosaic potyvirus cylindrical inclusion helicase interacts with the viral VPg and with lettuce translation eukaryotic initiation factor 4E. J Gen Virol. 2012:93(1):184-93.
25. German-Retana S, Candresse T, Alias E, Delbos RP, Le Gall O. Effects of green fluorescent protein or beta-glucuronidase tagging on the accumulation and pathogenicity of a resistance-breaking Lettuce mosaic virus isolate in susceptible and resistant lettuce cultivars. Mol Plant Microbe Interact. 2000;13:316-24.

26. German-Retana S, Redondo E, Tavert-Roudet G, Le Gall O, Candresse T. Introduction of a Nla proteinase cleavage site between the reporter gene and HC-Pro only partially restores the biological properties of GUS- or GFP-tagged LMV. Virus Res. 2003;98:151-62.

27. Jiang J, Laliberté JF. The genome-linked protein VPg of plant viruses - A protein with many partners. Curr Opin Virol. 2011;1:347-54.

28. Rajamäki M-L, Valkonen JPT. Control of nuclear and nucleolar localization of nuclear inclusion protein a of picorna-like Potato virus A in Nicotiana species. Plant Cell. 2009;21:2485-502.

29. Dinkel H, Van Roey K, Michael S, Davey NE, Weatheritt RJ, Born D, et al. The eukaryotic linear motif resource ELM: 10 years and counting. Nucleic Acids Res. 2014;42:1-8.

30. Redondo E, Krause-Sakate R, Yang SJ, Lot H, Le Gall O, Candresse T. Lettuce mosaic virus pathogenicity determinants in susceptible and tolerant lettuce cultivars map to different regions of the viral genome. Mol Plant Microbe Interact. 2001;14:804-10.

31. Toth IK, Hyman LJ, Bertheau Y, Fréchon D. DNA amplification by polymerase chain reaction (PCR). In: Perombelon MCM, Van der Wolf JM, editors. Methods for the Detection and Quantification of Erwinia carotovora subsp. atroseptica (Pectobacterium carotovorum subsp. atrosepticum) on Potatoes: A Laboratory Manual. Invergowrie, Scotland: Scottish Crop Research Institute Occasional Publication Number 10; 2002. p. 44-65. 1.

\section{Submit your next manuscript to BioMed Central and take full advantage of:}

- Convenient online submission

- Thorough peer review

- No space constraints or color figure charges

- Immediate publication on acceptance

- Inclusion in PubMed, CAS, Scopus and Google Scholar

- Research which is freely available for redistribution 